\title{
DIREITOS HUMANOS NO DIÁLOGO INTERCULTURAL: UM DEBATE NECESSÁRIO
}

\author{
André Pinto Baracchini* \\ Charlon Luis Zalewski** \\ Samira Birck de Menezes***
}

\begin{abstract}
RESUMO: Muito há que se falar em direitos humanos, sob todas as óticas possíveis e imagináveis. Temos aqui, a intenção de demonstrar o entrelaçamento entre direitos humanos e as diversas culturas e ideologias; uma possível convergência. No aspecto político, a defesa global dos direitos humanos e a soberania dos Estados. O presente artigo também trata de uma problemática acerca da universalidade ou não dos Direitos Humanos, através de um diálogo intercultural. Tem por base uma metodologia que visa não a dar respostas certas e finais, mas suscitar as questões acerca do assunto. Discorre acerca da compreensão cultural, globalização; traça formas de se estabelecer o possível diálogo para uma concepção multicultural de Direitos Humanos, a qual é vislumbrada por Boaventura de Sousa Santos. Faz um paralelo entre relativismo e universalismo cultural, tendo como intrínseca a idéia de Direitos Humanos (lato sensu).

PALAVRAS-CHAVE: Direitos Humanos. Cultura. Universalismo. Relativismo. Diálogo.
\end{abstract}

ABSTRACT: There is a lot of to talk about human rights, from all possible and imaginables viewpoints. We have here the intention of demonstrating the interlinking between human rights and several cultures and ideologies; a possible convergence. In the political aspect, the global defense of the human rights and the sovereignty of states. This article also treat the problematic concerning universality or not of the Human Rights, through of a intercultural dialogue. Its metodology doesn't aim to give definitely answers, but to awaken the questions about the matter. It talks about the cultural compreension, globalozation; it sketchs forms of establishing the possible dialogue for a multicultural conception about Human Rights, wich is vislumbrate by Boaventura de Sousa Santos. It does a paralel between cultural relativism and universalism, wich has intrinsic idea of Human Rights (lato sensu).

KEY-WORDS: Human Rights. Cultura. Universalism. Relativism. Dialogue.

*Acadêmico do $4^{\circ}$ semestre do Curso de Direito da Universidade Federal de Santa Maria (UFSM).

**Acadêmico do $4^{\circ}$ semestre do Curso de Direito da Universidade Federal de Santa Maria (UFSM)

***Acadêmica do $4^{\circ}$ semestre do Curso de Direito da Universidade Federal de Santa Maria (UFSM)

\section{INTRODUÇÃO}

Primeiramente, far-se-ia necessário caracterizar ou conceituar o objeto do presente trabalho: os direitos humanos. Difícil, complexa ou até inviável tarefa, haja vista partirmos do pressuposto de que um conceito, como uma construção humana, é contingenciado por inúmeras variáveis e, portanto, passível de críticas e invalidações. Além disso, a própria "espinha dorsal", ou idéia geral, das exposições que serão apresentadas, busca não tomar posições como verdadeiras ou universais, aliás é essa a grande questão que nos motiva. E, por estarmos trabalhando diretamente no campo das ciências sociais, pode-se dizer que muito do que se produz flutua abstratamente num espaço de constante construção e reformulação, que é pensamento social-humano. Mas isso não nos furta de apresentarmos possíveis conceituações / idéias, pois algo precisa ser dito e tomado como referencial teórico.

Tomamos a concepção de Direitos Humanos em sua forma geral, lato sensu. Pois especializar-se, tendo uma visão diferente de cada cultura não seria assunto 
adequado para um artigo científico, mas para a elaboração de uma tese em vários volumes, o que, ainda assim, não seria suficiente. Basta lembrar que cada cultura tem uma história, e cada uma "carrega" uma bagagem relacionada diretamente com seus princípios, especialmente os correlatos aos direitos humanos.

Conforme Bobbio, os direitos humanos são categorias construídas histórica e culturalmente, de modo que, além de não nascerem "todos de uma vez e nem de uma vez por todas", nascem em - e para - determinados contextos culturais ${ }^{1}$.

Os direitos humanos podem ser entendidos como um conjunto de valores consagrados em instrumentos jurídicos internacionais ou nacionais destinados a fazer respeitar e concretizar as condições de vida que possibilitem a todo ser humano manter e desenvolver suas qualidades peculiares de inteligência, dignidade e consciência, e permitir a satisfação de suas necessidades materiais e espirituais.

A noção de direitos humanos implica que se trata de direitos atribuíveis a cada ser humano enquanto tal, que esses direitos são vinculados à qualidade de ser humano, não fazendo distinção entre eles (tal seria uma concepção universalista, que de certa forma não contempla as diferentes dimensões) ${ }^{2}$.

O diálogo intercultural de que se falará reflete exatamente a tensão: os direitos humanos seriam universais, conforme os concebemos hoje, ocidentalmente, ou não? Existem princípios ou valores universais? Eles seriam dissociáveis de sua matriz ocidental? Estes valores seriam suscetíveis de uma tradução ou transposição multicultural? Como proceder, então, a este diálogo intercultural? Como buscar uma concepção multicultural de direitos humanos? Como tratar e quais as implicações entre relativismos e universalismos culturais para os direitos humanos? Até que ponto a ingerência de entes nacionais / internacionais em defesa de Direitos Humanos não viola soberanias estatais e culturais? Em que medidas são válidas intervenções? Até que ponto ter valores relativos não justifica possíveis violações de direitos? Estas são algumas das questões que circundam o tema e que procuraremos discorrer (e não respondermos) no decorrer do presente artigo.

\section{DIREITOS HUMANOS: COMPREENSÕES ACERCA DE CULTURA}

O conceito de cultura aqui utilizado é o mais amplo possível: refere-se a toda a estrutura da vida de determinado grupo de pessoas, incluindo tanto as tradições, os 
costumes e as práticas como as instituiçõos políticas e religiosas. Sistema historicamente criado com tramas de significados; sistema de regras e práticas em que um grupo humano compreende, regula e estrutura suas vidas intelectual e coletiva.

Para Edward Tylor (séc.XIX) o termo inglês culture, tomado em seu amplo sentido etnográfico, "é todo esse complexo que inclui conhecimentos, crenças, arte, moral, leis, costumes ou qualquer outra capacidade ou hábitos adquiridos pelo homem como membro de uma sociedade" 3 .

Tal capacidade humana de criar cultura, segundo Oakley, "resulta de um cérebro mais volumoso e complexo" ${ }^{4}$. Elucidando, busquemos nesse contexto a idéia do ser humano como ente capaz de autonomia, consciência, inteligência e capacidade comunicativa. Como ser criativo-interativo lançado no meio social, materializa-se a cultura.

Ainda, Lèvi-Strauss lembra que a cultura surgiu no momento em que o homem convencionou a primeira regra ou norma ${ }^{5}$. Ou seja, ele imiscui com a sua cultura uma organização social. Por isso tratar, também, esse diálogo intercultural no sentido de cultura como materializadora de um ordenamento jurídico, de um sistema normativo legal; tal é a pluralidade de complexos jurídicos.

O comportamento humano natural, seus instintos, recebe sempre valores que os governem, modulem, norteiem. Perdidos em sua natureza, encontra-se pelos limites de uma cultura.

Despiciendo destacar que a cultura é dinâmica e não autóctone, não se faz por si mesma, tão independizado que não precise ou não tangencie outro possível sistema cultural. Conforme Laraia, sem difusão não seria possível o grande desenvolvimento atual da humanidade. Tal é a idéia da incompletude que a hermenêutica diatópica trabalha. Quanto a isso nos perguntamos: esse intenso encontro cultural (conforme percebemos pelos meios de comunicação) seria tão malévolo e conflituoso, como muitos entendem, eliminando-se particularidades, ou trata-se de mais um estágio de evolução social, necessário para uma nova configuração global? Não seria a transitoriedade do homem através de sua linha espaço-tempo do século XXI, na inconstância a que todas as sociedades estão submetidas? Tal seria a base para o diálogo...

\footnotetext{
${ }^{3}$ LARAIA, 2006. 
Conclui o mesmo autor que cada sistema cultural está sempre em mudança. Entender esta dinâmica é importante para atenuar o choque entre as gerações e evitar comportamentos preconceituosos. Da mesma forma que é fundamental para a humanidade a compreensão da diferença entre povos de culturas diferentes, é necessário saber entender as diferenças que ocorrem dentro do mesmo sistema. Este é o único procedimento que prepara o homem para enfrentar serenamente este constante e admirável mundo novo do porvir ${ }^{6}$.

\subsection{Interface entre cultura e direitos humanos}

Conforme Eduardo Rabossi, primeiro filósofo a fazer referência ao discurso sobre Direitos Humanos como uma espécie de cultura, "aqueles constituem componentes essenciais de nossa visão de mundo... existe uma cultura florescente dos Direitos Humanos... nós fazemos parte dela, estamos imersos nela" 7.

Buscamos uma relação mais íntima, mais paralela, pois é o que percebemos. Pode-se dizer que uma cultura vive e trabalha diretamente com os direitos humanos. A maneira como os concebemos está também inserida em determinado contexto cultural. A matéria-objeto de uma cultura seria os Direitos Humanos. De outra ponta do discurso, seria possível dizer que eles fazem uma cultura. Assim, trabalhamos com a idéia de coexistência, um inserido dentro do outro. Ora, então os Direitos Humanos são diversos, pois as culturas são diversas (ou vice-versa)? Não partamos dessa conclusão incisiva. A idéia é que analisando um caso concreto é quase que imprescindível considerar o binômio.

\section{2 Ética, Moral e Direitos Humanos}

Tais universos de sentido também se implicam num diálogo intercultural. Em linhas gerais, podemos tomar a moral mais ligada a valores, dos quais resultam normas que são consideradas corretas por uma determinada sociedade, num determinado espaço-tempo. Débora Diniz diz que ao falar-se em relativismo cultural a expressão, muitas vezes cai espontaneamente e relativismo moral. A ética instrumentaliza-se na intersubjetividade, na relação com o outro, num respeito mútuo e solidário; ainda, conforme Rita Segato, há um "pulsão ética", que seria "el principio que promueve la expansón de los derechos Fundamentales em su movimiento universal" ${ }^{8}$. 


\subsection{Globalização e cultura: a mídia difusora}

Para Warnier, falar de globalização da cultura é um abuso de linguagem, pois "não é a cultura que está sendo globalizada, mas apenas determinados mercados de bens culturais" 9 . Ou seja, para ele, o elemento político-econômico é direcionador do tratamento que hoje damos à cultura e Direitos Humanos. Cada política econômica comporta um setor cultural.

Dentro dessa perspectiva, o diálogo entre as culturas, sob a lógica do mercado capitalista, entra o elemento mídia como ferramenta da globalização, como principal difusora da interculturalidade, mostrando as inúmeras "culturas" e comportamentos humanos apreciáveis.

Tomando a globalização como a tendência homogeneizadora, da cultura global do mundo interdependente, é pela massificação dos meios de comunicação, em que as informações nos são dadas a todo momento, que nos tornamos cientes desse multiculturalismo. A difusão midiática, como uma possível detentora e manipuladora do pensamento social pode, muitas vezes, subliminarmente, irradiar modelos de padrões de vida sócio-culturais que incutem a idéia dos direitos humanos universais, uma fonte universalista.

Mas podemos pensar sob outra perspectiva. Ao invés de universalizar (no sentido homogeneizar), não seria a mídia (televisão e internet, por exemplo) o responsável pela percepção do diferente, pelo diálogo e relativização cultural, que contemplaria a coexistência de diversos locos sociais e uma possível tolerância? Também. A mídia é sim, capaz disso; mas o problema não é, muitas vezes, o que ela mostra, mas a maneira como exterioriza as diferenças.

\section{DIREITOS HUMANOS: UMA PRETENSÃO GLOBAL}

Os direitos humanos surgiram como parte da política da Guerra Fria. Frequientemente os direitos humanos são hoje utilizados para preencher o vácuo deixado pelo colapso do socialismo, reinventando assim a linguagem de emancipação. Neste sentido, seguem determinados procedimentos, certos fenômenos culturais, originadores de, segundo Boaventura de Souza Santos ${ }^{10}$, tensões dialéticas, quais sejam: a) 
Regulação Social x emancipação Social; b) Estado x Sociedade Civil e c) Estado-Nação e Globalização.

Concomitantemente, é importante que se destaque, o fato de que para os direitos humanos se tornarem entes globais, capazes de incluírem um número cada vez maior de situações e culturas, além de angariar maior legitimidade em decorrência disto, deverão atuar em conjunção, em rede.

A Conferência de Viena foi um marco da discussão universalidade-relativização dos Direitos Humanos. Desde então, existe a preocupação entre a diversidade cultural. Reafirmou os quatro princípios que são o ponto central do regime com direitos humanos: os direitos humanos são universais (direitos que pertencem a todas as pessoas), indivisíveis (os direitos não podem ser separados uns dos outros), interrelacionados (os direitos afetam-se uns aos outros) e interdependentes (um direito não pode ser obtido integralmente sem que os outros também o sejam) ${ }^{11}$.

\section{PROPOSTAS ACERCA DE UM DIÁLOGO INTERCULTURAL}

\subsection{Hermenêutica Diatópica e Compreensão Intercultural}

Trata-se de uma espécie de método, "ferramenta", para proceder-se a um diálogo intercultural.

De acordo com Sousa Santos, no diálogo travado entre culturas diferentes, ocorre uma troca de universos de sentido diferentes, muitas vezes incompatíveis entre si ${ }^{12}$. Esses universos de sentido consistem em constelações de topoi fortes. Ou seja, cada universo de sentido possui seus próprios topos, que "são os lugares comuns retóricos mais abrangentes de determinada cultura". Em outras palavras, são os locais de onde emergem premissas de argumentação evidentes e irrefutáveis de determinada cultura, sobre as quais deve recair qualquer tentativa de diálogo intercultural.

Além disso, busca também, trazer um observador de "fora" da cultura em análise, que possa vislumbrar o cruzamento dos diferentes topoi.

A hermenêutica diatópica baseia-se na idéia de que os topoi de uma cultura, por mais fortes que sejam, são tão incompletos quanto a própria cultura a que pertencem. Tal é uma das premissas para que se estabeleça um diálogo e um dos objetivos dessa hermenêutica- ampliar a consciência da incompletude - , quanto mais incompleta,

\footnotetext{
${ }^{11}$ AMBROSI, 2005.

${ }^{12}$ SANTOS, 2003.
} 
melhor. Mas, a maneira como isso se dá, nas palavras do próprio autor, é “com um pé em uma cultura e outro em outra" - tal qual a idéia do paradigma da tradução, como veremos adiante.

Ela não requer apenas um tipo de conhecimento diferente, mas também um diferente processo de criação desse conhecimento, numa esfera coletiva, participativa, interativa e intersubjetiva. Uma produção baseada em trocas cognitivas e afetivas ${ }^{13}$. Enfim, leva a uma concepção híbrida - multicultural - de direitos.

\subsection{Boaventura de Souza Santos}

O que mais nos baseamos para discorrer acerca do assunto, por ser este grande teórico. Parte da idéia de que os direitos humanos, como são hoje entendidos e difundidos, baseiam-se na idéia de universalismo feita pelas concepções ocidentais, aliás, é essa a crítica: não há uma matriz universal para os direitos humanos. Consiste em transformar a concepção de direitos humanos como um localismo globalizado num projeto cosmopolita, de forma a realizar a transformação cosmopolita dos direitos humanos. Procura, assim, traçar o caminho para uma concepção multicultural de direitos humanos, "uma concepção que, em vez de recorrer a falsos universalismos, se organiza como uma constelação de sentidos locais, mutuamente inteligíveis, e que se constitui em redes de referências normativas capacitantes" ${ }^{14}$.

Confia o diálogo intercultural através da hermenêutica diatópica, que, em síntese, consiste na compreensão mútua dos distintos universos de sentido - topois- das culturas envolvidas.

Fala em um "trabalho de tradução", que visa esclarecer o que une e o que separa os diferentes movimentos e as diferentes práticas, de modo a determinar as possibilidades e os limites da articulação ou agregação entre eles. Ou seja, Boaventura busca a valorização do todo cultural ${ }^{15}$.

\section{AS POLÍTICAS EMANCIPATÓRIAS}

A grande questão, a "grande sacada" dos direitos humanos é beirar entre o caráter global e a legitimidade local. 
(...) conferir aos direitos humanos tanto o caráter global quanto a legitimidade local, para fundar uma política progressista de direitos humanos - direitos humanos concebidos como a energia e a linguagem de esferas públicas locais, nacionais e transnacionais atuando em rede para garantir novas e mais intensas formas de inclusão social ${ }^{16}$.

Para respeitar tanto os direitos humanos sob a ótica global quanto a local, um projeto cosmopolita, são grandes os desafios, e cinco as premissas capazes de levar à transformação teórica e prática dos direitos humanos, de forma a conceitualizá-los e aplicá-los como multiculturais, seguindo o pensamento de Boaventura ${ }^{17}$ :

$\checkmark$ Superação do debate sobre o universalismo e relativismo cultural: aduz-se que é incorreta a idéia firme de que existe um debate bipolar entre o universalismo e o relativismo cultural. Que as controvérsias não somente chocam-se, mas unem-se em prol da dignidade humana, que existem valores máximo que são respeitados, inexistindo um embate entre pontos extremos, mas diálogos.

$\checkmark$ Transformação cosmopolita dos direitos humanos: todas as culturas tem concepções a ver com a dignidade humana, mas não "absorvem", concebem, a idéia de direitos humanos. Essas culturas deveriam entender os princípios de dignidade humana como próprios dos direitos humanos.

$\checkmark$ Todas as culturas são incompletas e problemáticas nas suas concepções de dignidade humana: incompletude essa que tornou possível a diversidade, as diferenças, culturais. O importante é a consciência dessa incompletude, para se tornar possível uma concepção multicultural dos direitos humanos.

$\checkmark$ Todas as culturas têm versões diferentes de dignidade humana: existem diferentes prioridades, princípios mais predominantes que outros, e essas questões devem ser analisadas para definir quais serão os de maior presença no cenário multicultural. Tal desilusão ocasionaria a "vontade" de estabelecer um diálogo com as demais com intuito de autocompletar-se. Aqui surge a questão do medo de uma dominação cultural e de autodestruição ao manter-se esse contato. Mas, o que deve haver é ponderação entre a absorção de outras culturas e autodeterminação como participante de um determinado grupo.

$\checkmark$ Todas as culturas tendem a distribuir as pessoas e os grupos sociais entre dois princípios competitivos de vínculo hierárquico: igualdade versus diferença deve haver

\footnotetext{
${ }^{16}$ SANTOS, 2003.
}

${ }^{17}$ Ibid. 
uma distinção, uma aproximação, de certa forma, e não uma sobreposição destes princípios, para travarem-se lutas eficazes.

\section{ENTRELAÇAMENTO ENTRE SOBERANIA E DIREITOS HUMANOS}

Após 1945, período que sucedera a Segunda Grande Guerra, e a posterior democratização do Direito Internacional com a criação de vários novos Estados e o surgimento da Organização das Nações Unidas acentuaram os aspectos que limitariam a soberania, uma vez que hoje é subordinada à ordem jurídica internacional. Assim sendo, podemos extrair que os principais desdobramentos da soberania são o dever de nãoingerência na área de jurisdição exclusiva dos outros Estados e sua subordinação ao Direito Internacional. Isto posto, soberania é o feixe de competências que o estado possui e que lhe é outorgado pela ordem jurídica internacional. No começo do século XXI a sociedade internacional, por um lado definido pela interação cultural devido ao avanço dos meios de informação, pelo processo de globalização da economia as distâncias foram reduzidas, não há em como falar em soberania absoluta.

O divisor de águas, o marco do processo de internacionalização dos direitos humanos foi a Declaração Universal dos Direitos Humanos de 1948, que definiu os novos contornos da ordem pública mundial baseada, sobretudo no respeito à dignidade humana ao consagrar a universalidade e indivisibilidade dos direitos que tutelam a pessoa humana,com um conseqüente corpo normativo internacional para a tutela desses direitos. Isto posto, para a proteção desses direitos houve a reestruturação do conceito de soberania, em que inclusive permitem que Estados que não estejam pautados no respeito aos direitos humanos sejam responsabilizados no plano internacional em caso de violação dos mesmos.

Como destaca Garcia:

Reconhecendo-se que os direitos humanos aglutinam valores verdadeiramente essenciais a qualquer grupamento, daí derivando sua fundamentalidade e a correlata necessidade de imperativo respeito pelos estados, tornou-se inevitável e impostergável uma releitura do conceito de soberania ${ }^{18}$.

\section{A UNIFICAÇÃO DOS DIREITOS HUMANOS: UNIVERSALISMO E RELATIVISMO CULTURAL (E DOS DIREITOS HUMANOS)}

${ }^{18}$ GARCIA, 2007. 
As normas de direitos humanos podem ter um sentido universal ou são culturalmente relativas? Essa é a grande problemática da discussão sobre os direitos humanos atualmente.

Para os relativistas, a noção de direitos está estritamente relacionada ao sistema político, econômico, cultural, social e moral vigente em determinada sociedade. Acreditam que o pluralismo cultural impede a formação de uma moral universal, tornando-se necessário que se respeite as diferenças culturais apresentados por cada sociedade, bem como seu peculiar sistema moral.

$\mathrm{Na}$ percepção relativista, a pretensão de universalidade desses instrumentos simboliza a arrogância do imperialismo cultural do mundo ocidental, que tenta universalizar suas próprias crenças. $\mathrm{O}$ universalismo induz, nesta visão, à destruição da diversidade cultural.

A esta crítica reagem os universalistas, alegando que a posição relativista revela o esforço em justificar graves casos de violações dos direitos humanos que ficariam imunes ao controle internacional. Argumenta-se que a existência de normas universais pertinentes ao valor da dignidade humana é uma exigência do mundo contemporâneo.

A Declaração de Viena, 1993, que foi um marco para a discussão universalismo/relativismo, estabeleceu em seu parágrafo $5^{\circ}$ que "Todos os direitos humanos são universais, indivisíveis, interdependentes e inter-relacionados". A comunidade internacional deve tratar os direitos humanos globalmente, sob o pressuposto de existirem padrões mínimos de proteção dos direitos humanos.

Quanto às afirmações incontestes, revestidos de uma ingênua idéia posicionada a uma causa, pondera Diniz:

O reconhecimento de que todas as crenças são, em alguma medida, uma crença no nada, apesar de este ser um pressuposto aniquilante para os personagens moralizados, deve ser posto na ordem do dia para a mediação dos conflitos morais. A desnaturalização das certezas seria o primeiro passo para o exercício da tolerância ${ }^{19}$.

Nesse intento, Perelman propõe uma teoria dos direitos humanos associada a uma dialética do razoável. Mas esse razoável "se elabora a mercê do concurso de todos os seres humanos suscetíveis de se integrarem no auditório universal e necessita do confronto de suas idéias, do conhecimento de suas reações efetivas" 20.

\footnotetext{
${ }^{19}$ DINIZ, 2001.

${ }^{20}$ PELERMAN, 2005.
} 
Segundo Sousa Santos, o debate sobre universalismo e relativismo cultural é intrinsecamente falso, uma vez que todas as culturas são relativas e, ao mesmo tempo, aspiram valores válidos independentemente do contexto de sua enunciação. Ele joga a tensão universalismo/relativismo para dentro das culturas. Quer dizer: a tensão que antes parecia dizer respeito à visão "externa" que se tem acerca da validade das culturas em si e entre si, passa a representar uma contradição interna e intrínseca a todas as culturas.

Para exemplificar o debate, transcrevemos o questionamento de um representante chinês na II Conferência Mundial de Direitos Humanos, em Viena, acerca da universalização:

O conceito de direitos humanos é produto do desenvolvimento histórico. Encontra-se intimamente ligado a condições sociais, políticas e econômicas específicas, e à história, cultura e valores específicos, de um determinado país. Diferentes estágios de desenvolvimento histórico contam com diferentes requisitos de direitos humanos. Países com distintos estágios de desenvolvimento ou com distintas tradições históricas e backgrounds culturais também têm um entendimento e prática distintos de direitos humanos ${ }^{21}$.

\section{E o contraponto, por um representante de Portugal:}

É óbvio que este princípio de universalidade é compatível com a diversidade cultural, religiosa, ideológica e que a própria variedade de crenças, de idéias, e de opiniões dos homens é uma riqueza a defender e tem um valor próprio que importa respeitar. Mas argumentar com esta diversidade para limitar os direitos individuais, como infelizmente se registra aqui e além, não é permissível, nem em termos da lógica, nem em termos da moral ${ }^{22}$.

Porém, é de bom tom salientar que, apesar da guarda dos direitos humanos dever ser difundida perante as nações e minimamente uniforme para que se evite distorções em nome do que se entende por cultura local, tal constatação jamais deve servir de fundamento para a legitimação de intervenções de cunho imperialistas, visto que tais incursões estão apenas comprometidas com interesses individuais, ao contrário do que argúem os que as defendem, destituídas de boa fé e sentimento coletivo. O consagrado princípio da proporcionalidade deve ser interpretado consoante às peculiaridades de cada caso, levando-se em conta a natureza dos interesses envolvidos na discussão e a amplitude do bem a ser sacrificado, cominando-se isto tudo com bom senso a quem competir a decisão. A contrário senso, corre-se o risco de transformar a sistemática de

\footnotetext{
${ }^{21}$ Declaração de Nobuo Matsunaga, enviado do governo japonês e representante do Japão. Viena, 15/06/1993 apud CANÇADO TRINDADE (2003). ${ }^{22}$ Declaração de Dr. José Manuel Durão Barroso, Ministro dos Negócios Estrangeiros de Portugal. Viena, 16.06.1993 apud CANÇADO TRINDADE (2003).
} 
difusão dos direitos humanos em uma "fábrica" de argumentos a favor de guerras, notoriamente nefastas à convivência harmônica entre os indivíduos.

Acerca da Declaração Universal dos Direitos Humanos de 1948, Garcia destaca:

Nem todas as tradições culturais têm tido ou têm o mesmo valor a partir da perspectiva do reconhecimento, desenvolvimento e garantia dos direitos humanos. Uma Declaração Universal dos direitos fundamentais é incompatível com a defesa do relativismo cultural e moral. Isso significaria que a universidade dos direitos tem preferência sobre a preservação de identidades culturais antidireitos ${ }^{23}$.

\section{CONSIDERAÇÕES FINAIS}

É inegável o dilema acerca da compreensão de direitos humanos numa perspectiva universal frente os desafios das diversidades culturais.

Embora seja prudente que existam valores que devam ser considerados universais, não podemos fechar os olhos paras as diferenças. Tal é a reconstrução necessária acerca do atual paradigma de direitos humanos.

Nas palavras de Bobbio,

Num discurso geral sobre os direitos do homem, deve-se ter a preocupação inicial de manter a distinção entre teoria e prática, ou melhor, deve-se ter em mente, antes de mais nada, que teoria e prática percorrem duas estradas diversas e a velocidades muito desiguais ${ }^{24}$.

Ou seja, é preciso observar os fatos sociais na sua especificidade e particularidade, na aplicabilidade direta dos conceitos ora compreendidos. A justiça se faz mais, dizem os juristas, no caso concreto. E essa é a filosofia da modernidade, que se encontra em sintonia com a heterogeneidade.

É preciso estabelecer o diálogo intercultural, baseado na tolerância e compreensão mútua, para que os Direitos Humanos também sejam pensados sob novos horizontes contemplativos; para que se criem espaços de diálogo entre as culturas com vistas a estreitar o vínculo valorativo entre toda a humanidade e, dessa forma, alcançar uma universalidade legítima dos direitos humanos; e para o surgimento de um consenso normativo universal de normas e valores.

Além disso, não podemos deixar de discorrer a respeito do dinamismo dos direitos humanos, conforme Ambrosi com maestria coloca, e que não poderia ser incluído de outra forma senão citado diretamente:

\footnotetext{
${ }^{23}$ FERNÁNDEZ-GARCÍA (2001) apud GARCIA (2007, p.85)

${ }^{24}$ BOBBIO, 1992.
} 
“Os direitos humanos estão sujeitos a uma interpretação dinâmica e parte de sua essência é seu reconhecimento como padrão em um determinado contexto em um dado momento. Isso exige a análise de como os direitos humanos são influenciados pelo desenvolvimento atual, como a base de um determinado direito pode ser potencialmente ameaçada, como isso pode ser melhorado $e$ - o fator crucial - em que extensão o sistema de proteção existente é adequado e eficaz, dada a realidade dos novos desenvolvimentos tecnológicos. $\boldsymbol{O}$ órgão internacional de direitos humanos está assim em evolução perpétua para rejeitar novas ameaças, assim como para englobar novas oportunidades para sua expansão. Historicamente, essa evolução foi sempre o resultado de lutas sociais conduzidas por diferentes grupos em conjunturas históricas específicas" $(\text { grifo nosso })^{25}$."

\section{REFERÊNCIAS BIBLIOGRÁFICAS}

AMBROSI, Alain. Desafios das Palavras: enfoques multiculturais sobre as sociedades de informação. São Paulo: C \& F Éditions, 2005.

AMY, Marcelo. Uma visão islâmica das normas internacionais de direitos

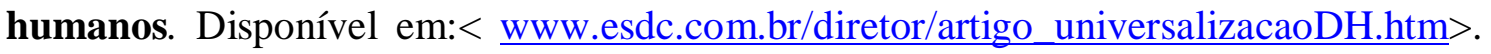
Acesso em 20 maio 2007. Artigo originalmente publicado na Coleção Pensamento e Criatividade, n. 5 - Filosofia e Educação: O Ocidente e os Orientes, 2006 - p. 71-83.

ALMEIDA, Fernando Barcellos. Teoria Geral dos Direitos Humanos. Porto Alegre: Fabris, 1996.

BOBBIO, Norberto. A era dos Direitos. Rio de Janeiro: Campus, 1992.

DINIZ, Débora. Antropologia e o Limite dos Direitos Humanos: o Dilema Moral de Tashi. Rio de Janeiro: Editora da Universidade Federal Fluminense, 2001.

GARCIA, Emerson. Influxos da ordem jurídica internacional na proteção dos direitos humanos: o necessário redimensionamento da noção de soberania. In: NOVELINO, Marcelo. (Org.). Leituras Complementares de Direito Constitucional. 2. ed. rev. e ampl. [S.1]: PODIVM, 2007.

GUARESCHI, Pedrinho. et. al. Psicologia, Ética e Direitos Humanos. São Paulo: Casa do Psicólogo, 2000.

LARAIA, Roque de Barros. Cultura: um conceito antropológico. 19. ed. Rio de Janeiro: Jorge Zahar, 2006.

PERELMAN, Chäim. Ética e Direito. 2. ed. São Paulo: Martins Fontes, 2005.

PIOVESAN, Flávia. Direitos Humanos e o Direito Constitucional Internacional. 3. ed. São Paulo: Max Limond, 1997.

SANTOS, Boaventura de Sousa. Para uma sociologia das ausências e das emergências. Disponível em: $\langle$ http://www.ces.uc.pt/bss/documentos/sociologia_das_ausencias.pdf $>$. Acesso em: 19 jun. 2007.

${ }^{25}$ AMBROSI, 2005. 
(org.). Reconhecer para Libertar: Os Caminhos do Cosmopolitismo

Multicultural. Rio de Janeiro: Civilização Brasileira, 2003.

SEGATO, Rita Laura. Antropología y derechos humanos: alteridad y ética en el movimento de los derechos humanos. Série Antropologia. Brasilia: UnB, 2004.

CANÇADO TRINDADE, Antonio Augusto. Tratado de direito internacional dos direitos

Humanos. V. III. Porto Alegre: Fabris, 2003.

WARNER, Jean-Pierre. A mundialização da cultura. Tradução: Viviane Ribeiro. Bauru - SP: EDUSC, 2000. 
